\title{
Blepharospasm: a review of 264 patients
}

\author{
F GRANDAS, ${ }^{*}$ J ELSTON, $\dagger$ N QUINN, * C D MARSDEN* \\ From the University Department of Neurology, Institute of Psychiatry and King's College Hospital Medical \\ School,* and Moorfields Eye Hospital, $\dagger$ London, UK
}

SUMMARY The natural history and response to different treatments have been evaluated in 264 patients with blepharospasm. The mean age of onset was 55.8 years and there was a female preponderance of 1.8 to 1 . Dystonia elsewhere was found in $78 \%$ of patients, usually in the cranialcervical region, and appeared to follow a somatotopic progression. A family history of blepharospasm or dystonia elsewhere was found in $9.5 \%$ of cases, which suggests a genetic predisposition. Ocular lesions preceded the onset of blepharospasm in $12.1 \%$ of cases. The response to drugs was inconsistent, although initial improvement was experienced by one fifth of patients treated with anticholinergics. Twenty-nine bilateral facial nerve avulsion operations were performed with benefit in 27 cases; but recurrences appeared in 22, on average one year after surgery. Botulinum toxin injections were performed in 151 patients. Significant improvement was achieved in 118 cases. Mean duration of benefit was $\mathbf{9 \cdot 2}$ weeks. Transient ptosis and diplopia were the commonest side effects.

Blepharospasm, ${ }^{1}$ repetitive involuntary sustained contractions of orbicularis oculi, is now believed to be a neurological disease. As a result of increased publicity and general awareness of this disabling condition, more and more patients are being recognised throughout the world. Prevalence data are limited, but a survey of the Mayo Clinic register estimated a figure of about 5 per 100,000 (Nutt, unpublished observations). There may therefore be some 3,000 affected individuals in the United Kingdom. To assist neurologists and ophthalmologists in advising patients with blepharospasm on the possible precipitants and inheritance of their illness, its natural history and chances of remission, and the outcome of the various treatment options for this condition, we present here a review of 264 patients seen at Moorfields Eye Hospital and the Maudsley Hospital.

\section{Patients and results}

The case notes of the 264 patients were reviewed to obtain answers to a standard questionnaire. Where there were gaps

$\ddagger$ Present address: Departimento Neurologia, Clinica Universitaria, Apartado 192, Pamplona, Spain.

Address for reprint requests: Dr Niall Quinn, University Department of Neurology, Institute of Psychiatry, De Crespigny Park, London SE5 8AF, UK.

Received 7 September 1987 and in revised form 4 January 1988. Accepted 5 January 1988 in the information, the patient was contacted or seen again in the clinic to obtain the missing data.

The mean age of onset was 55.8 (SD 12.5) years (range $11-81)$. There were 170 females $(64.4 \%)$ and 94 males $(35 \cdot 6 \%)$. The female/male ratio was $1 \cdot 8: 1$.

\section{Antecedent events}

There was a psychiatric illness before or at onset of blepharospasm in 47 cases $(17 \cdot 8 \%)$. Twenty nine patients $(11 \%)$ were depressed; two had a bipolar manic-depressive illness; $10(3.8 \%)$ suffered an anxiety state; four were schizophrenic; two had a single unspecified psychotic episode. Fourteen of these cases $(5 \cdot 3 \%$ of the total series) were exposed to neuroleptics before the onset of their blepharospasm, so may have been examples of tardive dystonia. Thus, only 33 patients $(13.2 \%)$ with non-tardive blepharospasm had a prior history of psychiatric disorder.

Thirty two cases $(12 \cdot 1 \%)$ had experienced local ocular disease in the year before the onset of their blepharospasm. In addition, a larger number of patients $(55.3 \%)$ complained of ocular symptoms prior to or at the onset of their blepharospasm (table 1 ). However, only 13 patients $(4.9 \%)$ developed new eye problems later during the course of their blepharospasm. The commonest complaints were of irritation, watering or grittiness of the eyes. Pain occurred in only 2 cases.

\section{Family history}

A history of movement disorders in other first or second degree family members was given by 52 cases $(19 \cdot 7 \%)$. Relatives, either affected or unaffected, were not examined in this study (indeed many of them were already deceased). Subsequent experience has shown that, at least as far as dystonia is concerned, the number of relatives affected by 
Table 1 Ocular symptoms and signs in 264 cases of blepharospasm

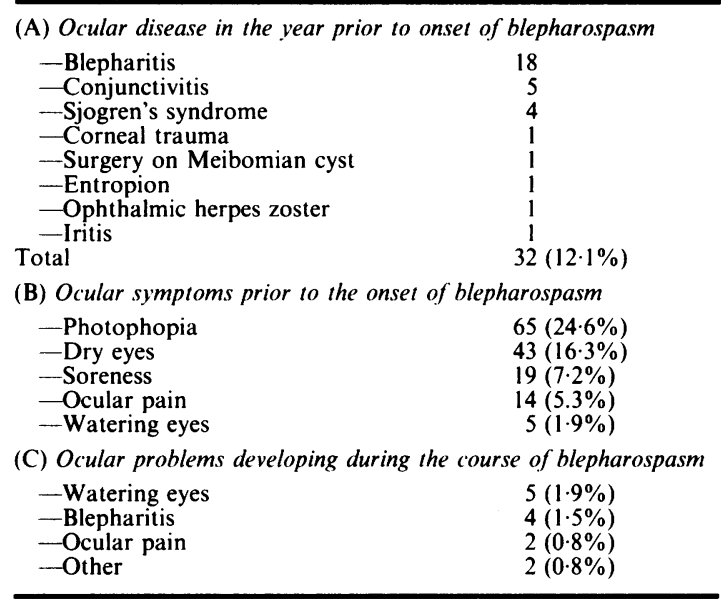

history represents a considerable underestimate of actually affected cases.

Blepharospasm itself occurred in six cases $(2 \cdot 3 \%)$, and increased blinking in nine cases $(3 \cdot 4 \%)$. Dystonia other than blepharospasm occurred in other family members in 10 cases $(3.8 \%)$. If increased blinking is considered an early manifestation of blepharospasm, a total of 25 patients $(9.5 \%)$ had a family history of dystonia. Other conditions reported in the family of some patients were Parkinson's disease (11 cases) and essential tremor ( 9 cases), which is not more than expected by chance. In addition, two patients had a family history of tics, and one each of Huntington's chorea, Sydenham's chorea and orofacial dyskinesia.

\section{Clinical features}

The onset was unilateral in 52 cases $(19.7 \%)$ but the blepharospasm became bilateral in all but four patients. The mean interval between the onset of unilateral blepharospasm and the spread to the other eye was 2 (SD 5.8) years. Ninety eight cases $(37 \cdot 1 \%)$ experienced excessive blinking before typical spasms occurred. The mean interval from the onset of blinking to the appearance of spasms was 7.9 (SD 14.5) years.

The intensity and frequency of spasms were increased by bright lights in $50.7 \%$, watching television in $47.7 \%$, reading in $35.6 \%$, stress in $42 \%$ and driving in $28.4 \%$. Blepharospasm improved after sleep in $32.8 \%$, relaxation in $29.2 \%$, concentration in $25.7 \%$, looking down in $7.2 \%$, and movements involving the oro-facial area such as talking, yawning, singing, and grimacing in $25.4 \%$. Many patients $(17 \%)$ had special "tricks" in order to open the eyes, such as touching or pulling the eyelids slightly; these may be regarded as the equivalent the "geste antagoniste" seen in other forms of dystonia.

Many patients were severely disabled by their blepharospasm before treatment. Approximately two-thirds of patients were rendered functionally blind to the extent that they were judged to require surgery or botulinum toxin injections to restore vision. Many had to give up work, or could not leave the house alone because they were "blind".
Table 2 Distribution of dystonia in 264 cases of blepharospasm

\begin{tabular}{lc}
\hline Orbicularis oculi & $264(100 \%)$ \\
Oro-mandibular & $188(71 \cdot 2 \%)$ \\
Neck & $60(22 \cdot 7 \%)$ \\
Laryngeal & $46(17 \cdot 4 \%)$ \\
Respiratory & $39(14 \cdot 8 \%)$ \\
Arm/Hand & $26(9 \cdot 8 \%)$ \\
Pharyngeal & $19(7 \cdot 2 \%)$ \\
Trunk & $6(2 \cdot 3 \%)$ \\
Leg/Foot & $5(1.9 \%)$ \\
Abdomen & $1(0 \cdot 4 \%)$ \\
\hline
\end{tabular}

Fear of crossing roads or bumping into objects often led to individuals becoming recluses. The mean interval from the onset of blepharospasm to severe visual disability was $2 \cdot 1$ (SD 3.6) years (range 0.5-30 years).

Blepharospasm was the only dystonic feature in 58 cases $(22 \%)$. In 206 patients $(78 \%)$ blepharospasm was associated with dystonia elsewhere (table 2). The lower facial and jaw muscles were most commonly affected (in $71 \cdot 2 \%$ ). The neck $(22.7 \%)$, and the laryngeal $(17.4 \%)$ and respiratory muscles $(14.8 \%)$ were the other areas most likely to be involved. There tended to be an orderly temporal progression of dystonia in the cranio-cervical area (table 3). A postural tremor of the arms, similar to that of benign essential tremor, was evident in $33(12.5 \%)$ of patients.

\section{Symptomatic blepharospasm}

The cause of the blepharospasm was unknown in 226 of the 264 patients. In a small number of patients, blepharospasm was secondary to Parkinson's disease (19 cases), progressive supranuclear palsy ( 3 cases), multiple system atrophy (1 case), and a unilateral lesion in the upper brainstem and thalamus ( 1 case). Fourteen of the patients were exposed to neuroleptic drugs prior to the onset of blepharospasm, developing tardive dystonia.

\section{Remission}

Thirty cases $(11.4 \%)$ experienced a partial or complete remission lasting at least a month. Fourteen patients had a complete remission, but there was recurrence in 13 of these after periods of time from 1 month to 40 years. Sixteen patients had a partial remission, but of these 12 had recurrence after 1 month to 6 years. Four patients had more than one remission. At the time of survey five patients were in remission for periods of between 1 to 6 years.

\section{Drug treatment}

The therapeutic response of blepharospasm to different drugs is described in table 4 . Each drug was given in gradually increasing dosage to the maximum tolerated. The

Table 3 Time of onset of dystonia elsewhere after the appearance of blepharospasm in 206 cases

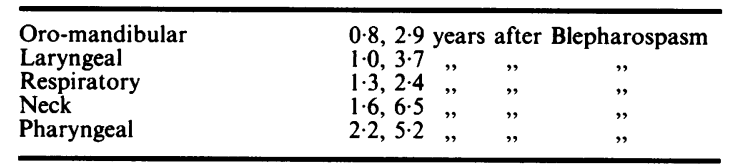

Mean, 1 SD years after onset of blepharospasm is shown. 
Table 4 Drug treatment of blepharospasm

\begin{tabular}{lccc}
\hline Drug & $\begin{array}{l}\text { No patients } \\
\text { treated }\end{array}$ & $\begin{array}{l}\text { No patients } \\
\text { with benefit }\end{array}$ & $\%$ \\
\hline Anticholinergics & 96 & 20 & $20 \cdot 8$ \\
Levodopa & 34 & 7 & $20 \cdot 6$ \\
Lisuride & 14 & 4 & $28 \cdot 6$ \\
Bromocriptine & 7 & 1 & $14 \cdot 3$ \\
Tetrabenazine & 52 & 3 & $5 \cdot 7$ \\
Haloperidol & 28 & 4 & $14 \cdot 2$ \\
Pimozide & 36 & 2 & $5 \cdot 5$ \\
Chloropromazine & 7 & 1 & $14 \cdot 3$ \\
Antidepressants & 25 & 3 & 12 \\
Benzodiazepines & 38 & 1 & $7 \cdot 8$ \\
Propranolol & 14 & 1 & $16 \cdot 7$ \\
Lithium & 6 & & \\
\hline
\end{tabular}

The effects of drug treatment were assessed by retrospective review of the case records. All patients were treated with maximum tolerated doses of the individual drugs. Benefit was defined as the restoration of some useful vision.

groups of drugs most often found to be of benefit were anticholinergics (in particular trihexiphenidyl or Artane), dopamine agonists (levodopa, bromocriptine and lisuride), and dopamine antagonists (tetrabenazine, and neuroleptic drugs such as haloperidol, pimozide and chlorpromazine). No consistent pharmacological profile was evident. Only about a fifth of the patients benefited from drug treatment, but if successful, drug therapy was effective in restoring functional vision and avoided the need for other treatment. However, initial benefit often was not sustained.

\section{Surgery}

Before the advent of botulinum toxin injections, 29 bilateral facial nerve avulsion operations were performed in 22 patients (by Professor Alan Bird). Restoration of useful vision was achieved on 27 occasions $(93 \cdot 1 \%)$. There was recurrence in $22(75.9 \%)$ after a mean of 11.7 (SD 10.7) months, but usually not to the same extent as originally. Unwanted effects were lower facial paralysis (11 cases), lagophthalmos ( 7 cases), persistent Bell's phenomenon (4 cases), eyelid droop ( 3 cases), ectropion (2 cases), corneal exposure ( 1 case) and accumulation of parotid secretions (1 case).

Seven patients underwent excision or stripping of the orbicularis oculi muscles, one of them twice (by Mr R Collin). Only two patients experienced significant benefit, and in one of these there was recurrence after 4 months. Unwanted effects were forehead numbness, bilateral ptosis and cosmetic problems.

Table 5 Effects of botulinum toxin injections on vision in 151 patients with blepharospasm

\begin{tabular}{ll}
\hline Degree of improvement & No patients \\
\hline $75-100 \%$ & $55(36 \cdot 4 \%)$ \\
$50-75 \%$ & $39(25 \cdot 8 \%)$ \\
$25-50 \%$ & $24(15 \cdot 9 \%)$ \\
Less than 25\% & $11(7 \cdot 3 \%)$ \\
Unknown (follow-up too short) & $22(14 \cdot 6 \%)$ \\
\hline
\end{tabular}

The degree of improvement was assessed by prospective estimation of the percentage of the waking day spent functionally blind, before and after the injection of botulinum toxin injections.
Table 6 Unwanted temporary effects of botulinum toxin injections for blepharospasm in 151 patients

\begin{tabular}{ll}
\hline Description & No patients \\
\hline Partial ptosis & 67 \\
Diplopia & 17 \\
Facial weakness & 7 \\
Local bruising & 5 \\
Ectropion & 4 \\
Generalised weakness & 3 \\
Dysphagia & 2 \\
Blurred vision & 2 \\
Dysphonia & 1 \\
Brow droop & 1 \\
Painful injection & 1 \\
\hline
\end{tabular}

Other surgical procedures were performed in several cases, namely alcohol injections into orbicularis oculi (1 case), thermolytic lesion of facial nerves (1 case), blepharoplasty (4 cases), neurectomy of the orbital branches of the facial nerves ( 1 case) and unilateral stereotactic thalamotomy (1 case). In only one patient of those treated by blepharoplasty was the outcome successful. The remaining cases only obtained transient or no benefit.

\section{Botulinum toxin injections}

One hundred and fifty one cases were treated with injections of type A Botulinum toxin obtained from Vaccine Research and Development Laboratories, Centre for Applied Microbiological Research, Porton Down, UK. Doses for a single treatment of both eyes ranged from 0.4 to $2.2 \mathrm{ng}$ of neurotoxin. However, the dose in almost all cases initially was $1.3-1.6 \mathrm{ng}$ of neurotoxin, often reducing to $0.8 \mathrm{ng}$ after several treatments. It should be noted that these doses are of the neurotoxin itself, not those of the haemagglutinin complex, and that they refer only to neurotoxin obtained from Porton Down.

The mean duration of improvement was 9.2 (SD 5.5) weeks. One hundred and eighteen patients $(78 \cdot 1 \%)$ achieved a significant improvement (table 5). Fifty-five patients (36.4\%) had relatively normal vision restored. Another 39 $(25.8 \%)$ were no longer functionally blind, but still had some residual visual deficit, whilst the remaining 24 (15.9\%) had only limited improvement in vision.

After treatment with botulinum toxin injections, 49 patients $(32.4 \%)$ remarked on improvement of their lower facial and/or oromandibular dystonia.

Side effects are described in Table 6. Sixty-seven patients (44.3\%) had transient (1-35 days) unilateral or bilateral ptosis. Seventeen cases $(11 \cdot 3 \%)$ had transient ( $1-45$ days) diplopia. Seven cases $(4 \cdot 6 \%)$ had significant but transient (1-10 days) lower facial weakness.

Persistent disabling problems emerged after botulinum toxin injections in 23 cases $(15 \cdot 2 \%)$. Fifteen patients $(9.9 \%)$ had a persistent spontaneous Bell's phenomenon, six (3.9\%) experienced persistent levator inhibition, and two (1.3\%) had levator disinsertion. These problems prevented complete restoration of useful vision. Levator disinsertion, however, could be corrected by minor oculoplastic surgery.

\section{Discussion}

Blepharospasm is a focal dystonia which appears 
mainly in women, usually in the sixth decade. ${ }^{1-6}$ Its cause is not known. A genetic predisposition is suggested in a minority of patients by a family history of a similar disorder. ${ }^{367}$ We found blepharospasm or increased blinking in close family members in 2.3 and $3.4 \%$ respectively. Increased blinking frequently is the first sign of blepharospasm. So in our series some $5.7 \%$ of cases gave a family history of a similar disorder. Blepharospasm frequently co-exists with other manifestations of dystonia. ${ }^{38}$ In the present series, $78 \%$ had evidence of dystonia elsewhere than in the periocular muscles. Dystonia other than blepharospasm occurred in other family members in $3.8 \%$ of our patients. So, in total, $9.5 \%$ of this series of patients with blepharospasm had a history of some type of dystonia in other family members.

Blepharospasm very often was associated with dystonia elsewhere, principally involving the cranialcervical area. Oromandibular dystonia was the commonest association. Less than $10 \%$ presented dystonic features lower than the neck. Blepharospasm usually preceded oromandibular dystonia, and this preceded torticollis when all occurred in the same patient. These data, if confirmed in other large series, might indicate a somatotopic progression of dystonia.

Most cases of blepharospasm have no other identifiable disease. In our series, an obvious cause was evident only in $14.3 \%$ of patients. These included Parkinson's disease and other forms of Parkinsonism, ${ }^{9-12}$ neuroleptic-induced tardive dystonia $^{1314}$ (other drugs including levodopa ${ }^{15}$ and nasal decongestants ${ }^{16}$ may also precipitate blepharospasm), and occasional focal structural lesions in basal ganglia, ${ }^{1718}$ diencephalon, ${ }^{19}$ or upper brainstem. ${ }^{20-23}$ However, no consistent pathology has been found in the few cases of idiopathic blepharospasm that have come to necropsy. ${ }^{24}{ }^{25}$ We have also examined the brains of three patients with blepharospasm and/or oromandibular dystonia; one was found to have a brainstem angioma, but no abnormality was discovered in the other three.

The pathophysiology of blepharospasm has been explored recently. The high incidence of excessive blinking prior to the onset of frank periocular muscle spasms (37.1\% in our series) suggests a disorder of the blink reflex. ${ }^{26}$ Electrophysiological studies have revealed abnormalities of the electrically-induced blink reflex in patients with blepharospasm. ${ }^{2728}$ Most conspicuous are enlargement and prolongation of the R2 component, with an enhanced recovery cycle of the $R 2$ after paired stimulation. This suggests that the lower brainstem pathways responsible for the blink reflex are intact, but that the interneurons conveying the late $\mathbf{R} 2$ component are hyperexcitable or disinhibited. Since most structural lesions identified as causing blepharospasm have been in the basal gan- glia or upper brainstem, the most reasonable hypothesis is that dysfunction of descending basal ganglia pathways causes hyperexcitability of the brainstem interneurons responsible for the blink reflex.

However, this abnormality of the blink reflex has also been found in some patients with lower cranial dystonia and even torticollis, but without blepharospasm; ${ }^{28}$ we have confirmed this observation (unpublished observations). This suggests that something else is required to trigger frank blepharospasm in those predisposed to this condition.

One clue to such a trigger is the high incidence of local ocular symptoms and signs prior to or at the onset of blepharospasm. In our series, $56.8 \%$ of patients reported local ocular symptoms (photophobia, dry eyes, soreness, ocular pain or watering eyes) prior to or at the onset of their blepharospasm, and $12.1 \%$ had signs of local eye disease. It is most unlikely that these ocular symptoms and signs were due to the blepharospasm, for only $4.9 \%$ of the patients developed such problems later in the course of the established disease. The suggestion is that in many cases local eye disease may trigger blepharospasm in those so predisposed. A similar role for local trauma precipitating a focal dystonia in some cases also has been suggested for spasmodic torticollis, ${ }^{29}$ writer's cramp ${ }^{30}$ and other dystonias. ${ }^{31}{ }^{32}$

In a past era, blepharospasm was often attributed to psychiatric illness or psychological disorders. However, only a minority of patients have overt psychiatric illness prior to the onset of their blepharospasm; excluding those with neuroleptic induced blepharospasm, only $13.2 \%$ of cases in this series had a psychiatric illness prior to or at the onset of their blepharospam. This is not likely to be of significance.

Turning to treatment, only about one in five of our patients gained benefit from drug therapy. Many drugs have been claimed to relieve blepharospasm,,$^{33-39}$ but there is no consistent pharmacological response..$^{40-42}$ Anticholinergic drugs probably give the best chance of benefit, ${ }^{43-46}$ but side effects are common and the response is inconsistent. The chances of drugs helping are confounded by the problem of spontaneous remissions of the condition. Such remissions, which were temporary in most patients, were reported in $11.4 \%$ of our cases. It is difficult to decide whether improvement of blepharospasm on drug therapy is due to the pharmacological effects of the drug, a placebo response, a spontaneous remission or a drug-induced remission. Controlled trials are necessary to resolve these questions, but few have been undertaken in blepharospasm.

Different surgical approaches were tried to relieve blepharospasm. Bilateral avulsion of facial nerves ${ }^{478}$ was the most successful, producing initial improvement in more than $90 \%$ of the patients. 
Unfortunately recurrences were frequent (75\%), occurring on average one year after surgery, although then not as disabling as the original illness. Muscle stripping of orbicularis oculi ${ }^{4-50}$ was initially successful in only $25 \%$ of patients so treated. Other surgical approaches such as alcohol injections or thermolytic lesions of facial nerves, ${ }^{51}$ produced only temporary benefit.

Injection of botulinum toxin type $A$ into orbicularis oculi has recently been introduced for the treatment of blepharospasm. ${ }^{52-59}$ Botulinum neurotoxin binds to peripheral motor nerve terminals and inhibits the release of acetylcholine ${ }^{60-61}$ Botulinum toxin injections produced a significant improvement in more than $75 \%$ of the treated patients, with almost complete disappearance of blepharospasm in one third. The benefit is maintained on average between 9 and 10 weeks, which implies that injections should be repeated about five times a year, however occasional patients benefit for considerably longer periods.

Side effects are common but usually local and transient. Nevertheless botulinum toxin injections is so far the best therapeutic measure that can be offered to patients with disabling blepharospasm.

\section{References}

1 Meige $H$. Les convulsions de la face. Une forme clinique de convulsion faciale, biláterale et médiane. Rev Neurol (Paris) 1910;21:437-43.

2 Paulson G. Meige's syndrome. Dyskinesia of the eyelids and facial muscles. Geriatrics 1972;27:69-73.

3 Marsden CD. Blepharospasm-oromandibular dystonia syndrome (Brueghel's syndrome). A variant of adult-onset torsion dystonia? J Neurol Neurosurg Psychiatry 1976;39:1204-9.

4 Tolosa ES. Clinical features of Meige's disease. (Idiopathic orofacial dystonia). A report of 17 cases. Arch Neurol 1981; 38: 147-51.

5 Jankovic J, Ford J. Blepharospasm and orofacial-cervical dystonia: Clinical and pharmacological findings in 100 patients. Ann Neurol 1983;13:402-11.

6 Jankovic J, Orman J. Blepharospasm: Demographic and clinical survey of 250 patients. Ann Ophthalmol 1984;16:371-6.

7 Nutt JG, Hammerstad JP. Blepharospasm and oromandibular dystonia (Meige's syndrome) in sisters. Ann Neurol 1981; 9:189-91.

8 Marsden CD. The problem of adult-onset idiopathic torsion dystonia and other isolated dyskinesias in adult life (including blepharospasm, oromandibular dystonia, dystonic writer's cramp, and torticollis, or axial dystonia). Adv Neurol 1976; 14:259-76.

9 Alpers BJ, Patten CA. Paroxysmal spasm of the eyelids as a postencephalitic manifestation. Arch Neurol Psychiat 1927; 29:427-33.

10 Corin MS, Elizan TS, Bender MB. Oculomotor function in patients with Parkinson's disease. J Neurol Sci 1972;15:251-65.

11 Klawans HL, Erlich MA. Observations on the mechanism of parkinsonian blepharospasm and its treatment with L-dopa. Eur Neurol 1970;3:365-72.

12 Jackson JA, Jankovic J, Ford J. Progressive supranuclear palsy: clinical features and response to treatment in 16 patients. Ann Neurol 1983;13:273-8.

13 Weiner WJ, Nausieda PA, Glantz RH. Meige syndrome (blepharospasm-oromandibular dystonia) after long-term neuroleptic therapy. Neurology 1981;31:1555-6.

14 Burke RE, Fahn S, Jankovic J et al. Tardive dystonia: late-onset and persistent dystonia caused by antipsychotic drugs. Neuro$\log y$ 1982;32:1335-46.

15 Weiner WJ, Nausieda PA. Meige's syndrome during long-term dopaminergic therapy in Parkinson's disease. Arch Neurol 1982;39:451-2.

16 Powers JM. Decongestant-induced blepharospasm and orofacial dystonia. JAMA 1982;247:3244-5.

17 Keane JR, Young JA. Blepharospasm with bilateral basal ganglia infarction. Arch Neurol 1985;42:1206-8.

18 Jankovic J. Blepharospasm with basal ganglia lesions. Arch Neurol 1986;43:866-8.

19 Powers JM. Blepharospasm due to unilateral diencephalon infarction. Neurology 1985;35:283-4.

20 Jankovic J, Patel SC. Blepharospasm associated with brainstem lesions. Neurology 1983;33:1237-40.

21 Day JJ, Lefroy RB, Mastaglia FL. Meige's syndrome and palatal myoclonus associated with brain stem stroke. A common mechanism? J Neurol Neurosurg Psychiatry 1986;49:1324-5.

22 Lang AE, Sharpe JA. Blepharospasm associated with palatal myoclonus and communicating hydrocephalus. Neurology 1984;34:1522.

23 Leenders KL, Frackowiak RSJ, Quinn N, Brooks D, Sumner D, Marsden CD. Ipsilateral blepharospasm and contralateral hemidystonia and parkinsonism in a patient with a unilateral rostral brainstem-thalamic lesion: Structural and functional abnormalities studied with CT, MRI and PET scanning. Movement Disorders 1986;1:51-8.

24 Garcia-Albea E, Franch O, Munoz D, Ricoy JR. Brueghel's syndrome, report of a case with postmortem studies. $J$ Neurol Neurosurg Psychiatry 1981;44:437-40.

25 Altrocchi PH, Forno LS. Spontaneous oral-facial dyskinesia: Neuropathology of a case. Neurology 1983;33:802-5.

26 Jankovic J, Havins WE, Wilkins RB. Blinking and blepharospasm. Mechanisms, diagnosis and management. JAMA 1982;248:3160-4.

27 Berardelli A, Rothwell JC, Day BL, Marsden CD. Pathophysiology of blepharospasm and oromandibular dystonia. Brain 1985;108:593-608.

28 Tolosa ES, Montserrat L, Bayes A. The blink reflex in dystonia. Advances in Neurology 1988 (in press.)

29 Sheehy MP, Marsden CD. Trauma and pain in spasmodic torticollis. Lancet 1980;i:777-8.

30 Sheehy MP, Marsden CD. Writer's cramp-a focal dystonia. Brain 1982;105:461-80.

31 Schott GD. The relationship of peripheral trauma and pain to dystonia. J Neurol Neurosurg Psychiatry 1985;48:698-701.

32 Brin MF, Fahn S, Bressman SB, Burke RE. Dystonia precipitated by peripheral trauma. Neurology 1986;36 (Suppl 1):119.

33 Miller E. Dimethylaminoethanol in the treatment of blepharospasm. N Engl J Med 1973;289:697.

34 Chakravorty NK. Treatment of blepharospasm with levodopa. Postgrad Med J 1974;50:521-3.

35 Merikangas JR, Reynolds CE. Blepharospasm: successful treatment with clonazepam. Ann Neurol 1979;5:401-2.

36 Skarf JB, Sharpe JA. Choline for blepharospasm. $N$ Engl J Med 1981;305:957-8.

37 Jankovic J. Treatment of hyperkinetic movement disorders with tetrabenazine: a double-blind crossover study. Ann Neurol 1982;11:41-47.

38 Micheli F, Fernandez-Pardal MM, Leiguarda RC. Beneficial effects of lisuride in Meige's disease. Neurology 1982;322: $432-4$.

39 Duvoisin RC. Meige's syndrome: relief on high-dose anticholinergic therapy. Clin Neuropharmacol 1983;6:63-6.

40 Tolosa ES, Lai CW. Meige's disease: Striatal dopaminergic 
preponderance. Neurology 1979;29:1126-30.

41 Casey D. Pharmacology of blepharospasm-oromandibular dystonia syndrome. Neurology 1980;30:690-5.

42 Marsden CD, Lang AE, Sheehy MP. Pharmacology of cranial dystonia. Neurology 1983;33:1100-1.

43 Tanner CM, Glantz RH, Klawans HL. Meige's disease: Acute and chronic cholinergic effects. Neurology 1982;32:783-5.

44 Fahn S. High dosage anticholinergic therapy in dystonia. Neurology 1983;33:1255-61.

45 Nutt JG, Hammerstad JP, DeGarmo P, Carter J. Cranial dystonia: double-blind crossover study of anticholinergics. Neurology 1984;34:215-7.

46 Lang AE. High dose anticholinergic therapy in adult dystonia. Can J Neurol Sci 1986;13:42-46.

47 Talbot JF, Gregor Z, Bird AC. The surgical management of essential blepharospasm. In: Marsden CD, Fahn S, eds. Movement Disorders. London: Butterworths, 1982:322-9.

48 McCord CD, Coles WH, Shore JW, Spector R, Putnam JR. Treatment of essential blepharospasm. I. Comparison of facial nerve avulsion and eyebrow-eyelid muscle stripping procedures. Arch Ophthalmol 1984;102:266-8.

49 Gillum WN, Anderson RL. Blepharospasm surgery. An anatomical approach. Arch Ophthalmol 1981;99:1056-62.

50 McCord CD, Shore J, Putnam JR. Treatment of essential blepharospasm. II. A modification of exposure for the muscle stripping technique. Arch Ophthalmol 1984;102:269-73.

51 Battista AF. Surgical approach to blepharospasm: nerve thermolysis. In: Marsden CD, Fahn S, eds. Movement Disorders.
London: Butterworths, 1982:319-321.

52 Frueh BR, Felt DP, Wojno TH, Musch DC. Treatment of blepharospasm with botulinum toxin. Arch Ophthalmol 1984;102:1464-8.

53 Scott AB, Kennedy RA, Stubbs HA. Botulinum A toxin injection as a treatment for blepharospasm. Arch Ophthalmol 1985;103: $347-50$.

54 Tsoy EA, Buckley EG, Dutton JJ. Treatment of blepharospasm with botulinum toxin. Am J Ophthalmol 1985;99:176-9.

55 Elston JS, Russell RWR. Effect of treatment with botulinum toxin on neurogenic blepharospasm. $\mathrm{Br}$ Med J 1985;290: 1857-9.

56 Maurieelo JA. Blepharospasm, Meige's syndrome, and hemifacial spasm: treatment with botulinum toxin. Neurology 1985; 35:1499-1500.

57 Dutton JJ, Buckley EG. Botulinum toxin in the management of blepharospasm. Arch Neurol 1986;43:380-82.

58 Brin MF, Fahn S, Moskowitz C, et al. Injection of botulinum toxin for the treatment of focal dystonia. Neurology 1986;36(Suppl 1): 120.

59 Jankovic J, Orman J. Botulinum toxin for cranial cervical dystonia: a double-blind controlled study. Neurology 1986;36 (Suppl 1):120-1.

60 Kao I, Drachman DB, Price D. Botulinum toxin: Mechanism of presynaptic blockade. Science 1976;193:1256-8

61 Dolly OJ, Black J, Williams RS, Melling J. Acceptors for botulinum neurotoxin reside on motor nerve terminals and mediate its internalisation. Nature 1984;307:457-60. 